\title{
ALTERAÇÕES NA RUGOSIDADE SUPERFICIAL DO SOLO PELO PREPARO E PELA CHUVA E SUA RELAÇÃO COM A EROSÃO HÍDRICA ${ }^{(1)}$
}

\author{
Luciana Gomes Castro ${ }^{(2)}$, Neroli Pedro Cogo ${ }^{(3)} \&$ Leandro \\ Bocchi da Silva Volk ${ }^{(4)}$
}

\begin{abstract}
RESUMO
Apesar de efêmera, a rugosidade superficial no solo induzida por métodos de seu preparo é requerimento importante nos sistemas de manejo de caráter conservacionista. Isto se deve ao fato de que ela aumenta a retenção e a infiltração superficiais de água no solo, reduz a velocidade e o volume do escoamento superficial e aprisiona os sedimentos da erosão, diminuindo os danos causados pela erosão hídrica. Considerando tais aspectos, realizou-se esta pesquisa com o objetivo de avaliar as alterações ocorridas na rugosidade superficial do solo pelas ações do preparo e da chuva, na ausência e na presença de cobertura morta, em relação à erosão hídrica. O estudo foi realizado em campo, na EEA/UFRGS, em Eldorado do Sul (RS), em 1996 e 1997, aplicando-se chuva simulada sobre um Argissolo Vermelho distrófico típico, de textura francoargilo-arenosa e declividade de $0,07 \mathrm{~m} \mathrm{~m}^{-1}$. Avaliaram-se os preparos de solo aração, aração e duas gradagens e sem preparo, na ausência e na presença de $60 \%$ de cobertura por resíduo cultural, submetidos a quatro testes de chuva simulada. $\mathrm{O}$ primeiro teste foi constituído de uma chuva segmentada, composta de quatro porções, com durações de $20,20,30$ e 30 min, espaçadas uma da outra de 30 a $40 \mathrm{~min}$, aplicada logo após o preparo do solo. Os demais testes foram constituídos de chuvas contínuas, com duração de $90 \mathrm{~min}$, aplicadas 1,20 e 35 dias após a primeira chuva. Tais chuvas foram aplicadas com o aparelho simulador de chuva de braços rotativos, na intensidade constante de $64,0 \mathrm{~mm} \mathrm{~h}^{-1}$. A alteração na rugosidade superficial do solo causada pelo preparo foi maior do que a causada pela chuva. O maior decréscimo na rugosidade superficial do solo pela ação da chuva ocorreu já no primeiro evento, logo após o solo ter sido preparado, antes do
\end{abstract}

\footnotetext{
(1) Parte da Tese de Mestrado do primeiro autor, apresentada ao Programa de Pós-Graduação em Ciência do Solo, Universidade Federal do Rio Grande do Sul - UFRGS. Apoio do Projeto CNPq-PRONEX/Solos, PIBIC-CNPq/UFRGS, FAPERGS e CNPq. Recebido para publicação em março de 2005 e aprovado em fevereiro de 2006

${ }^{(2)}$ Professora Assistente do Departamento de Engenharia Agrícola e Solo, Universidade Estadual do Sudoeste da Bahia. Caixa Postal 95, CEP 45083-900 Vitória da Conquista (BA). E-mail: lucastro@uesb.br

(3) Professor Adjunto, Departamento de Solos da Faculdade de Agronomia, Universidade Federal do Rio Grande do Sul - UFRGS. Caixa Postal 15100, CEP 91501-970 Porto Alegre (RS). Bolsista do CNPq. E-mail: neroli@ufrgs.br

(4) Doutorando do Programa de Pós-Graduação em Ciência do Solo, UFRGS. E-mail: levolk@bol.com.br
} 
início da enxurrada. A rugosidade superficial do solo impediu ou retardou a enxurrada nos tratamentos com solo mobilizado nos segmentos de chuva de curta duração, aplicados logo após o preparo, impedindo ou reduzindo as perdas de água e solo naquele período, independentemente da cobertura do solo. Nas chuvas contínuas subseqüentes, de longa duração, a rugosidade superficial do solo não influenciou a perda de água nos tratamentos com solo mobilizado na ausência de cobertura, sendo alta em todos eles, mas a influenciou na sua presença, diminuindoa com o aumento da rugosidade. $O$ tratamento sem preparo permaneceu com a perda de água elevada sempre em tais chuvas. Quanto à perda de solo, nas mesmas chuvas, o efeito da rugosidade na sua redução foi mais evidente na ausência de cobertura, tendo sido substancialmente ocultado na sua presença. A cobertura morta adicionada ao solo não preservou a elevada rugosidade superficial inicialmente criada pelos preparos no solo degradado utilizado no estudo. Mesmo assim, ao final do experimento, ainda restava mais da metade da capacidade teórica inicial de retenção de água e de sedimento nas microdepressões formadas pela rugosidade. Os dados obtidos foram consistentes com teorias e conceitos usados em estudos de mecânica de erosão hídrica do solo.

Termos de indexação: chuva simulada, preparo do solo, cobertura morta, perda de água, perda de solo.

\section{SUMMARY: ALTERATIONS IN SOIL SURFACE ROUGHNESS BY TILLAGE AND RAINFALL IN RELATION TO WATER EROSION}

\footnotetext{
Although being temporary, the presence of tillage-induced surface roughness in the soil is an important requirement in conservation tillage systems. The reason is that surface roughness increases both surface retention and surface infiltration of water in the soil, reduces runoff velocity and volume, and traps eroded sediments, thus reducing water erosion damages. With this in mind, this study was developed with the objective of evaluating modifications in soil surface roughness by tillage and rainfall actions related to water erosion, in the absence and presence of mulch cover. The experiment was carried out in the field, at the Agriculture Experimental Station of the Federal University of Rio Grande do Sul (EEA/UFRGS), in Eldorado do Sul County, Rio Grande do Sul State, Brazil, in 1996 and 1997, using simulated rainfalls on a sandy clay loam Paleudult with $0.07 \mathrm{~m} \mathrm{~m}^{-1}$ slope steepness. The tillage types evaluated in the study included plowing, plowing plus double-disking and no-till, all them in the absence and presence of $60 \%$ soil cover (oat residue), submitted to four simulated rainfall tests. The first test consisted of a rainfall segmented in four portions, lasting for 20, 20, 30, and $30 \mathrm{~min}$, separated 30 to $40 \mathrm{~min}$ from each other, applied immediately after tillage. The remaining tests consisted of uninterrupted rains of 90-min duration, applied 1, 20, and 35 days after the first rain. These rainfalls were applied with the rotating-boom rainfall simulator at a constant intensity of $64.0 \mathrm{~mm} \mathrm{~h}^{-1}$. Tillage caused greater changes in the soil surface roughness than rainfall. Soil surface roughness was most reduced by rain action in the very first event in recently-tilled soil, in the pre-runoff period. Soil surface roughness impeded or delayed runoff in treatments with soil mobilization in the rainfall segments with short duration applied soon after tillage, impeding or reducing water and soil losses in that period, regardless of soil cover. In the continuous, subsequent long rains, surface roughness did not influence water loss in the studied treatments without cover, where it was high throughout the experimental period, but it did reduced water loss in the presence of cover. Water loss in no-till was high for such rains throughout the experiment. Under the same rain type, soil loss reduction as influenced by roughness was more evident in the absence of cover, whereas it was substantially obscured in its presence. Mulch of crop residue added to the soil surface did not preserve the initially high surface roughness created by tillage in the degraded soil used in the study. Nevertheless, by the end of the experiment more than half of the theoretical initial water and sediment retention capacity still remained in the microdepressions formed by roughness. The obtained data were consistent with theories and concepts used in soil erosion mechanics studies.
}

Index terms: simulated rainfall, soil tillage, mulch cover, water loss, soil loss. 


\section{INTRODUÇÃO}

A cobertura por resíduos culturais e a rugosidade superficial induzida por métodos de preparo constituem as condições físicas de superfície do solo mais importantes do ponto de vista de redução da erosão hídrica. A cobertura é fundamental na dissipação da energia cinética das gotas da chuva, impedindo seu impacto direto na superfície do solo, enquanto a rugosidade é importante na retenção e na infiltração superficiais de água, na diminuição da velocidade e do volume da enxurrada e no aprisionamento dos sedimentos da erosão, com efeitos marcantes na conservação do solo e da água (Burwell et al.,1966; Allmaras et al., 1967; Cogo, 1981; Cogo et al., 1983, 1984). Estas duas variáveis são altamente dependentes do preparo do solo; contudo, o método de preparo a ser adotado em determinada área vai depender das condições de clima e solo locais, devendo ser ajustado a cada situação. O desconhecimento e, ou, a desconsideração destes fatos poderá levar os agricultores a utilizarem um método de preparo do solo inadequado para as suas condições, o que poderá acelerar a degradação das suas terras de cultivo (Larson \& Gill, 1973).

O asperezamento da superfície do solo é a alteração mais notável resultante do seu preparo, originando um microrrelevo ou rugosidade superficial no solo. Para Burwell et al. (1966), essa alteração poderá resultar em dois tipos de rugosidade: orientada e ao acaso. A rugosidade orientada caracteriza-se pela presença ordenada de elevações e depressões na superfície do solo, facilmente permitindo a identificação da direção do preparo, enquanto a rugosidade ao acaso caracterizase pela ocorrência irregular de picos e depressões, não permitindo, pois, por meio da observação visual, identificar a direção do preparo. Tanto a rugosidade superficial ao acaso quanto a orientada, esta última, porém, desde que disposta no sentido transversal ao do declive, reduzem as perdas água e solo por erosão hídrica, uma vez que aumentam a retenção e a infiltração superficiais de água no solo e reduzem o volume e a velocidade do escoamento superficial. Decorrente disso, a capacidade de desagregação e de transporte das partículas de solo pela ação da enxurrada é reduzida, induzindo a deposição dos sedimentos da erosão no local de ocorrência do fenômeno, por meio das microdepressões formadas pela rugosidade superficial do solo (Burwell et al.,1966; Cogo, 1981; Cogo et al., 1983, 1984; Bertol et al, 1987, 1989).

A excessiva e, ou, a contínua mobilização do solo pelo preparo, entretanto, reduz sua rugosidade superficial, fragmenta seus agregados e deixa sobre sua superfície maior quantidade de partículas desagregadas prontamente disponíveis para o transporte, o que contribui para diminuir a retenção e a infiltração superficiais de água e aumentar a enxurrada e a erosão (Burwell et al., 1966; Allmaras et al., 1967; Burwell \& Larson, 1969; Cogo, 1981). Em adição, a superfície de solo que sofre mais mobilização torna-se mais susceptível à erosão em sulcos, cuja enxurrada pode, também, remover os resíduos culturais nela existentes (Cogo, 1981; Cogo et al., 1996; Bertol et al., 1997; Morais \& Cogo, 2001). O aumento na intensidade de preparo do solo também reduz a sua cobertura por resíduos culturais, dada a sua incorporação parcial ou total no solo, tornando-o mais exposto à ação erosiva de impacto das gotas da chuva, favorecendo, mais ainda, a erosão hídrica (Wischmeier, 1973; Cogo, 1981).

A chuva, por sua vez, pode modificar as condições físicas de superfície do solo criadas pelo preparo, graças à desagregação de suas partículas pela ação combinada da chuva com sua enxurrada associada, reduzindo a rugosidade superficial e, conseqüentemente, a retenção e a infiltração superficiais de água no solo. Isso pode favorecer o selamento superficial, especialmente nas microdepressões da rugosidade, que vai refletir-se em maiores perdas de água e solo por erosão hídrica, principalmente nos solos com pouca ou nenhuma cobertura vegetal (Burwell \& Larson, 1969; Johnson et al., 1979; Cogo, 1981). Outros autores, como Burwell et al. (1966), Burwell \& Larson (1969) e Cogo et al.(1984), investigando a redução da rugosidade superficial do solo pela ação da chuva em solo recém-mobilizado, verificaram que o maior decréscimo ocorreu já nos primeiros eventos de chuva, antes do início da enxurrada.

Os solos que apresentam microrrelevo mais acentuado e, por conseguinte, maior rugosidade superficial, irão manter melhor sua capacidade de retenção e de infiltração superficiais de água, comparados aos solos com superfície lisa. Isto porque o selamento superficial preferencialmente ocorre nas microdepressões da superfície rugosa e em praticamente toda a extensão da superfície lisa (Larson, 1962). Por esta razão, a cobertura do solo por resíduos culturais assume grande importância junto ao papel desempenhado pela rugosidade superficial em termos de redução da erosão hídrica, uma vez que ela protege a superfície do solo contra a ação de impacto direto das gotas da chuva. Isso reduz tanto a desagregação das partículas de solo pela chuva, quanto a capacidade de transporte de sedimentos pela enxurrada, o que vai refletir-se em aumento da retenção e da infiltração superficiais da água no solo, diminuição do escoamento superficial e deposição imediata dos sedimentos erodidos (Wischmeier, 1973; Cogo, 1981; Lopes et al., 1987a,b; Bertol et al., 1989). A interação da rugosidade superficial do solo com a cobertura vegetal morta na redução da erosão hídrica também tem sido examinada (Burwell et al., 1966; Cogo, 1981; Norton et al., 1985; Bertol et al., 1987). Esses autores observaram maior efeito da rugosidade superficial 
do solo na redução da erosão hídrica sob baixos valores de cobertura do solo por resíduo cultural, argumentando que, sob níveis de cobertura mais elevados, o efeito é substancialmente ocultado por ela. De qualquer forma, a presença de rugosidade superficial no solo deve ser sempre almejada nas lavouras, tendo em vista a eficaz redução de ambas, perdas de água e solo por erosão hídrica.

Esta pesquisa foi realizada com o objetivo de avaliar as alterações ocorridas na rugosidade superficial do solo pelas ações do preparo e da chuva, em relação a alguns processos físico-hidrológicos de superfície determinantes da erosão hídrica, assistidos ou não pela cobertura do solo formada por resíduo cultural uniformemente distribuído sobre sua superfície, em solo com suspensão de cultivo. Além da possível aplicação prática imediata, os resultados obtidos neste estudo poderão mais tarde ser utilizados na derivação do fator C - cobertura e manejo do modelo "USLE/RUSLE" de predição da erosão hídrica (Wischmeier \& Smith, 1978; Renard et al., 1997).

\section{MATERIAL E MÉTODOS}

A pesquisa foi realizada em campo, na Estação Experimental Agronômica da Universidade Federal do Rio Grande do Sul (EEA/UFRGS), em Eldorado do Sul (RS), durante 1996 e 1997. O solo no local do experimento é um Argissolo Vermelho distrófico típico (Streck et al., 2002), de textura franco-argiloarenosa na camada superficial, horizonte B textural, profundidade e drenagem moderadas e declividade média de $0,07 \mathrm{~m} \mathrm{~m}^{-1}$, sendo bastante susceptível à erosão em sulcos, especialmente quando preparado.

Para início da pesquisa, o solo da área experimental foi retirado do processo de cultivo e submetido a freqüentes escarificações e gradagens, durante 1,5 ano, para eliminação da vegetação existente, seguido de um ano sob pousio descoberto e sem preparo do solo, em processo de reconsolidação natural. Assim, no momento da investigação propriamente dita, o solo encontrava-se relativamente consolidado e degradado e, nessa condição, foram instalados, sem repetição e de forma próxima à completamente casualizada (em função da natureza da pesquisa), os seguintes tratamentos: (a) aração, 0 \% de cobertura, (b) aração, 60 \% de cobertura; (c) aração e duas gradagens, $0 \%$ de cobertura; (d) aração e duas gradagens, $60 \%$ de cobertura; (e) sem preparo, $0 \%$ de cobertura e (f) sem preparo, $60 \%$ de cobertura. A cobertura foi composta por resíduo cultural de aveia (Avena sativa), trazido de outro local, o qual foi uniformemente distribuído na superfície do solo nas parcelas experimentais. A aração foi feita com arado de três discos, com diâmetro de 0,66 m, e as gradagens com grade niveladora de 28 discos, recortados na frente e lisos atrás, com diâmetro de
0,51 m. As operações de preparo do solo foram efetuadas no sentido do declive do terreno, conforme filosofia de obtenção de valores para o fator C cobertura e manejo do modelo "USLE/RUSLE" de predição da erosão hídrica (Wischmeier \& Smith, 1978; Renard et al., 1997).

Sobre os tratamentos supradescritos, foram aplicados quatro testes de chuva simulada (exceto no tratamento sem preparo, o qual, por problemas surgidos no aparelho simulador de chuva, não foi submetido às chuvas segmentadas do primeiro teste). O primeiro teste (T1) foi constituído de uma chuva (C) segmentada, composta por quatro porções (C1, C2, C3 e C4), com durações de 20, 20, 30 e 30 min, espaçadas entre si de 30 a 40 min (para possibilitar a medição do microrrelevo da superfície do solo, para posterior cálculo do índice de rugosidade superficial), tendo sido aplicada logo após o preparo do solo. Os demais testes (T2, T3 eT4) foram constituídos de chuvas contínuas, com duração de 90 min, aplicadas 1, 21 e 36 dias após a primeira chuva. Registra-se aqui o fato de não terem ocorrido chuvas naturais com magnitude que pudesse ter interferido nos resultados da pesquisa em questão nos trinta e seis dias de realização dos testes de chuva simulada em campo. As chuvas foram aplicadas simultaneamente sobre duas parcelas experimentais, por meio do aparelho simulador de chuva de braços rotativos (Swanson, 1965), na intensidade constante de $64,0 \mathrm{~mm} \mathrm{~h}^{-1}$.

Imediatamente antes da implantação dos tratamentos, caracterizou-se o solo da área experimental nas camadas de $0-0,075$ e $0,075-$ $0,15 \mathrm{~m}$, em termos de teores de areia, silte e argila (método do hidrômetro), matéria orgânica (método da combustão úmida), atividade microbiana (método da liberação de $\mathrm{CO}_{2}$ ), densidade e porosidade total do solo (método do anel volumétrico), diâmetro médio ponderado dos agregados a úmido (método do peneiramento e oscilação mecânica em água) e índice de erodibilidade do solo - fator K do modelo "USLE/ RUSLE" de predição da erosão hídrica (dividindo a perda de solo observada no solo convencionalmente preparado e descoberto pela erosividade da chuva que a causou), como detalhadamente descrito em Castro (1998).

Antes da aplicação das chuvas simuladas, foram coletadas amostras de solo para determinação do teor de água no solo, em base gravimétrica, nas camadas de $0-0,10$ e $0,10-0,20 \mathrm{~m}$. A cobertura do solo pelo resíduo cultural foi avaliada pelo método fotográfico (Cogo, 1981). A rugosidade superficial do solo foi avaliada antes e depois do preparo do solo e depois de cada teste de chuva simulada, utilizando-se rugosímetro similar ao descrito por Kuipers (1957). O equipamento em questão apresentava $2,60 \mathrm{~m}$ de largura e $0,55 \mathrm{~m}$ de altura, com 100 varetas de alumínio verticalmente dispostas e espaçadas de $2,5 \mathrm{~cm}$, possibilitando a 
tomada de 100 leituras de elevações da superfície do solo, transversalmente, na porção superior, central e inferior de cada parcela, totalizando 300 leituras por tratamento. Adotou-se o desvio-padrão das alturas das elevações da superfície, em $\mathrm{cm}$, como índice de rugosidade superficial do solo, eliminandose, no entanto, antes do cálculo, os valores de elevações $10 \%$ maiores e $10 \%$ menores, para diminuir o erro causado por leituras erráticas, em procedimento similar ao descrito por Burwell et al.(1963) e Allmaras et al. (1967).

Durante a aplicação das chuvas, registrou-se o tempo necessário para iniciar o escoamento superficial, expresso em minutos. A partir desse momento, foram coletadas amostras de enxurrada, intermitentemente, a cada três minutos, para determinação da sua taxa instantânea de descarga, concentração instantânea de sedimentos, perda total de água e perda total de solo. Maiores detalhes sobre o modo como foram feitas essas medições podem ser obtidos em Cogo (1981) e Castro (1998). Os dados obtidos foram interpretados à luz de teorias e conceitos usados em estudos de mecânica de erosão hídrica do solo, sem nenhuma referência à significância estatística desses dados. Tal procedimento é válido em estudos dessa natureza, sendo comumente adotado por boa parte dos pesquisadores que investigam a erosão do solo nas condições reais de campo, sob a ação de chuva natural e, ou, de chuva simulada.

\section{RESULTADOS E DISCUSSÃO}

\section{Características do solo antes dos tratamentos}

Algumas características do solo após a adequação da área experimental e antes da implantação dos tratamentos estão apresentadas no quadro 1. Verifica-se que características importantes para a conservação do solo e da água, como conteúdo de matéria orgânica, atividade microbiana, densidade do solo, porosidade total, diâmetro médio ponderado dos agregados e índice de erodibilidade encontravam- se com seus valores desfavoráveis, indicando relativamente alto grau de degradação do solo. Isto era esperado, tendo em vista que a área experimental foi deliberadamente manejada de modo a deixar o seu solo degradado, inclusive suspendendo-se o cultivo do solo, para avaliar as relações da rugosidade superficial do solo com a erosão hídrica exatamente sob essa condição. Levou-se em conta, ainda, a intenção de repetir o estudo em etapa posterior, porém sob a condição de solo cultivado (com diferentes espécies culturais e por diferentes tempos de cultivo).

\section{Teor de água no solo antecedente às chuvas simuladas}

Tendo em vista a pequena variação observada nos valores de teor de água no solo antes da aplicação das chuvas simuladas entre tratamentos, tanto nas camadas de $0-0,10$ e $0,10-0,20 \mathrm{~m}$, quanto na ausência e na presença de cobertura morta, os resultados desta variável não estão sendo apresentados. No entanto, para informação, o teor médio de água no solo na camada de 0-0,10 m antes da aplicação das chuvas foi de $0,12 \mathrm{~kg} \mathrm{~kg}^{-1}$, com variação de 0,10 a $0,14 \mathrm{~kg} \mathrm{~kg}^{-1}$, e, na camada de 0,10 $0,20 \mathrm{~m}$, foi de $0,14 \mathrm{~kg} \mathrm{~kg}^{-1}$, com variação de 0,12 a $0,16 \mathrm{~kg} \mathrm{~kg}^{-1}$ (Castro, 1998). Assim, pode-se dizer que o teor de água no solo antecedente às chuvas simuladas aplicadas não constituiu fonte de variação no estudo.

\section{Alterações na rugosidade superficial do solo pelo preparo e pela chuva}

Os valores do índice de rugosidade superficial do solo, antes e depois do preparo e depois dos testes de chuva simulada estão apresentados na figura 1 . Chama-se a atenção para o fato de que as diferenças nos valores do índice entre as condições sem e com cobertura em tal figura devem-se apenas às variações decorrentes do preparo do solo em si e da irregularidade natural do terreno da área experimental, já que a cobertura morta foi adicionada às parcelas experimentais após as operações de preparo e as medições de rugosidade

Quadro 1. Características do solo utilizado no estudo antes dos tratamentos - decorridos 2,5 anos e 1 ano, respectivamente, da cessação do cultivo e do preparo do solo

\begin{tabular}{|c|c|c|c|c|c|c|c|c|c|}
\hline \multirow{2}{*}{ Camada de solo } & \multicolumn{4}{|c|}{ Granulometria } & \multirow{2}{*}{$\mathbf{A M}^{(2)}$} & \multirow{2}{*}{$\operatorname{Ds}^{(3)}$} & \multirow{2}{*}{$\mathbf{P} \mathbf{t}^{(4)}$} & \multirow{2}{*}{$\operatorname{DMP} \mathbf{P}^{(5)}$} & \multirow{2}{*}{$\mathbf{K}^{(6)}$} \\
\hline & Areia & Silte & Argila & $\mathbf{M O}^{(1)}$ & & & & & \\
\hline $\mathrm{m}$ & 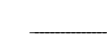 & $\mathrm{g}$ & 1 & - & mg C kg-1 solo & $\mathrm{kg} \mathrm{m}^{-3}$ & $\mathrm{~m}^{3} \mathrm{~m}^{-3}$ & $\mathrm{~mm}$ & \\
\hline $0-0,075$ & 574 & 235 & 191 & 21 & 218 & 1.600 & 0,37 & 0,64 & 0,034 \\
\hline $0,075-0,15$ & 569 & 225 & 206 & 20 & 458 & 1.600 & 0,38 & 0,61 & - \\
\hline
\end{tabular}

\footnotetext{
(1) Matéria orgânica. ${ }^{(2)}$ Atividade microbiana. ${ }^{(3)}$ Densidade do solo. ${ }^{(4)}$ Porosidade total. ${ }^{(5)}$ Diâmetro médio ponderado dos agregados
} a úmido. ${ }^{(6)}$ Fator erodibilidade do solo da Equação Universal de Perda de Solo, em unidades de Mg ha h (MJ ha mm)-1. 
terem sido executadas. Desta forma, não se podem comparar os valores de rugosidade no sentido vertical da figura 1 , entre as condições sem e com cobertura, num mesmo tratamento de preparo, mas, sim, no sentido longitudinal, em relação à mudança no tempo, ocasionada pela ação das chuvas simuladas aplicadas.

Antes do preparo do solo, na condição sem cobertura, os valores de rugosidade superficial diferiram levemente entre si (Figura 1), em razão da irregularidade natural do terreno da área experimental, sendo eles relativamente baixos (2,3 cm, na média dos locais de medição, destinados a cada tratamento de preparo), decorrente do suave microrrelevo do terreno no momento inicial do estudo, uma vez que o solo encontrava-se relativamente consolidado e com superfície praticamente lisa.

Após o preparo do solo, no entanto, a rugosidade superficial foi grandemente aumentada, atingindo valores de, até, 6,10 cm (aumento relativo de $197 \%$ ), observado no tratamento aração, na ausência de cobertura, em virtude de a mobilização do solo nesse tratamento ter sido feita apenas com o arado. O tratamento aração e duas gradagens, por sua vez, teve sua rugosidade superficial aumentada em $66 \%$ pelo preparo (passou de $2,76 \mathrm{~cm}$ para $4,58 \mathrm{~cm}$, na ausência de cobertura). O menor acréscimo na rugosidade superficial do solo pelo preparo na aração e duas gradagens deveu-se à maior fragmentação dos torrões e agregados de solo, atribuída à ação repetida da grade niveladora, a qual reduziu o índice de rugosidade em $30 \%$ (na média dos tratamentos de cobertura), comparado ao valor existente antes das gradagens (valor exclusivo da aração). Finalmente, o tratamento sem preparo foi o que apresentou menor valor do índice de rugosidade (1,72 cm - respectivamente 70 e $60 \%$ menor do que na aração e na aração e duas gradagens, na média dos tratamentos de cobertura). Além disso, por não ter havido mobilização de solo neste tratamento, sua rugosidade superficial não foi alterada.

Verifica-se, também na figura 1, que, a partir do primeiro segmento de chuva na aração e duas gradagens e do segundo segmento na aração, ambos do primeiro teste de chuva (respectivamente T1C1 e T1C2), a redução da rugosidade superficial do solo pela ação da chuva foi gradual e pequena, tendendo à estabilização ao final do último teste de chuva (T4), inclusive o tratamento sem preparo, independentemente da cobertura do solo. Isto confirma o fato de que a redução mais acentuada na rugosidade superficial do solo, por ação exclusiva da chuva, ocorre já nos primeiros eventos da chuva, no período pré-enxurrada (Burwell et al., 1966; Allmaras et al., 1967; Cogo, 1981; Cogo et al., 1983).

No estudo em questão, esse processo foi ainda intensificado pela fragilidade da estrutura do solo utilizado, como já comentado. Independentemente disso, na média dos tratamentos de cobertura, ao longo do experimento, a rugosidade superficial manteve-se mais elevada na aração do que na aração e duas gradagens, e estas duas mais do que no sem preparo. O primeiro fato é explicado pela maior resistência da superfície de solo arada à ação dos agentes erosivos, comparada à superfície de solo arada e gradeada, especialmente após a primeira acomodação do solo (que normalmente ocorre nas primeiras chuvas), resultante da menor fragmentação de solo pela ação mecânica somente do arado, enquanto o segundo é atribuído à grande diferença na rugosidade entre as condições sem e com preparo de solo. Verifica-se, ainda na figura 1, que a cobertura morta adicionada ao solo não preservou os elevados valores de rugosidade superficial inicialmente criados pelo preparo. Isto, provavelmente, pode ser explicado pelo fato de o solo utilizado no estudo encontrar-se degradado por ocasião da realização dos testes de chuva simulada, com agregados muito frágeis (Quadro 1).

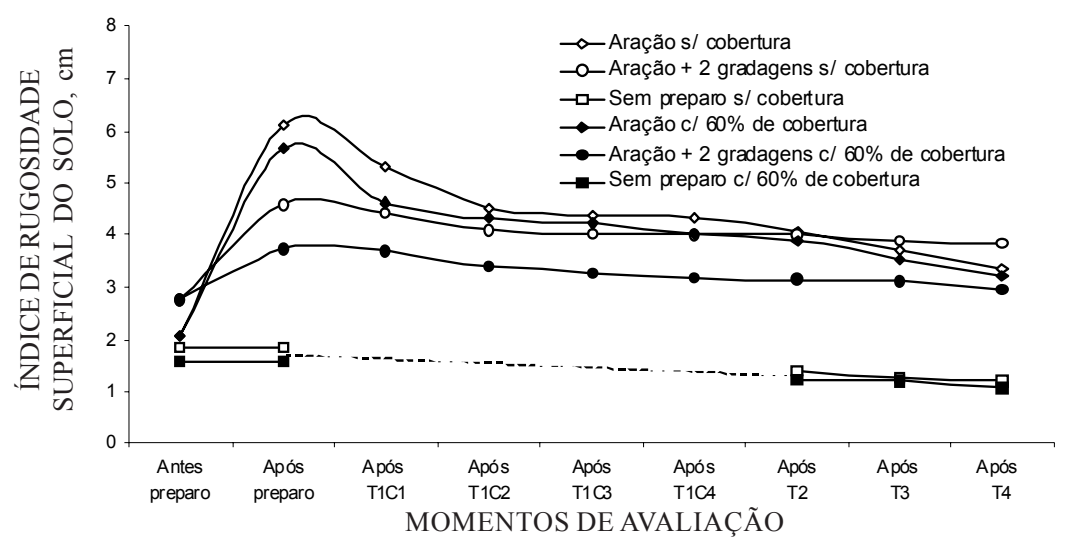

Figura 1. Índice de rugosidade superficial do solo no decorrer do experimento (T1, T2, T3 e T4 = testes de chuva 1, 2, 3 e 4, aplicados logo, 1, 20 e 35 dias após o preparo do solo, respectivamente; C1, C2, C3 e $\mathrm{C} 4$ = segmentos de chuva 1, 2, 3 e 4 de T1, com durações de 20, 20, 30 e 30 min, respectivamente; as chuvas dos Testes 2,3 e 4 foram contínuas e tiveram 90 min de duração). 
Quanto à alteração da rugosidade superficial do solo pela ação da chuva, comparada à ação do preparo, verifica-se, na figura 1 , que, nos tratamentos que sofreram mobilização de solo, o aumento da rugosidade pelo preparo foi bem maior do que a sua redução pela chuva, independentemente dos tratamentos avaliados, porém mais acentuadamente na aração. Pode-se constatar que, em termos relativos, na média dos tratamentos de cobertura, a aração aumentou a rugosidade superficial do solo em $187 \%$, enquanto o primeiro segmento de chuva do primeiro teste (T1C1) a reduziu em, apenas, $16 \%$; após o segundo segmento de chuva do primeiro teste (T1C2), a redução (acumulada) da rugosidade superficial neste mesmo tratamento ficou ainda em, apenas, $25 \%$. O tratamento aração e duas gradagens, por sua vez, também na média dos tratamentos de cobertura, aumentou a rugosidade superficial do solo em $50 \%$, enquanto o primeiro segmento de chuva do primeiro teste (T1C1) o reduziu em, apenas, $3 \%$; após o segundo segmento de chuva do primeiro teste (T1C2), a redução (acumulada) da rugosidade superficial, neste mesmo tratamento, ficou em, apenas, $10 \%$.

Destaca-se, agora, a redução relativa nos valores do índice de rugosidade superficial do solo nos tratamentos avaliados ao término do experimento, após a aplicação de $395 \mathrm{~mm}$ de chuva, no período de 36 dias de realização dos testes de chuva simulada. Como já referido, nesse período, não ocorreram chuvas naturais que pudessem ter causado alterações físicas consideráveis nas superfícies de solo em estudo. Assim, pode-se constatar que, no referido espaço de tempo, a rugosidade superficial do solo, na média dos tratamentos de cobertura, foi reduzida pela ação das chuvas aplicadas em 44, 18 e $34 \%$, respectivamente, na aração, aração e duas gradagens e sem preparo, em relação aos valores iniciais, existentes logo após as operações de preparo do solo e antes da aplicação do primeiro teste de chuva simulada. Tais reduções são consistentes com os tipos de superfície de solo resultantes das operações de preparo efetuadas e, embora consideráveis, verifica-se que, teoricamente, ao final do experimento, ainda restava mais da metade das capacidades iniciais de retenção de água e de sedimentos nas microdepressões formadas pela rugosidade superficial do solo (56 e $66 \%$, respectivamente na aração e aração e duas gradagens).

Não obstante seu efeito efêmero, a presença de rugosidade superficial no solo induzida por métodos de seu preparo é sempre desejável nas lavouras agrícolas, especialmente no que se refere à possibilidade real de conseguir maiores retenção e infiltração superficiais da água da chuva, bem como maior aprisionamento dos sedimentos da erosão nas microdepressões formadas por ela.

\section{Tempo de início da enxurrada}

Os resultados desta variável estão apresentados no quadro 2. Verifica-se que, na ausência de cobertura do solo, a enxurrada somente ocorreu ao final do segundo segmento de chuva na aração e duas gradagens e ao final do terceiro segmento na aração, ambos do primeiro teste de chuva (T1C2 e T1C3, respectivamente). Isto é explicado pela ainda relativamente alta rugosidade superficial do solo presente em tais preparos antes destes segmentos de chuva, a qual proporcionou elevadas capacidades de retenção e infiltração superficiais de água do solo (Johnson et al., 1979; Cogo, 1981), mesmo tendo ela sido já consideravelmente reduzida nos segmentos de chuva anteriores (Figura 1). O maior retardamento da enxurrada na aração deveu-se, certamente, à sua maior rugosidade superficial, conseqüentemente, à maior porosidade total da sua camada de solo preparada. A partir do terceiro segmento de chuva na aração e duas gradagens e do quarto segmento na aração, ambos do primeiro teste de chuva (T1C3 e T1C4, respectivamente), e a partir do segundo teste de chuva (T2) no sem preparo, a enxurrada iniciou já nos minutos iniciais de chuva, em todos os tratamentos estudados (Quadro 2). Isto é explicado pela diminuição da rugosidade superficial do solo pela ação das chuvas anteriores (Figura 1) e, muito provavelmente, pela contínua formação de selos e crostas, preferencialmente nas microdepressões da superfície de solo ainda rugosa nos tratamentos que sofreram mobilização de solo e em praticamente sobre toda a extensão da superfície de solo lisa no tratamento sem preparo.

Em que pese não ter tido influência na preservação dos elevados valores de rugosidade superficial inicialmente criados pelo preparo, como já discutido, a cobertura do solo de $60 \%$, formada por resíduo cultural, teve influência marcante no tempo de início da enxurrada nos tratamentos que sofreram mobilização de solo, aumentando-o em todos os testes de chuva, exceto no último (T4), mas não teve influência no tratamento sem preparo. Isto pode ser explicado pelos efeitos diferenciados que a cobertura morta e a rugosidade superficial do solo têm nos processos físico-hidrológicos que ocorrem na superfície do solo. Nos tratamentos com mobilização de solo, a cobertura morta protegeu as condições físicas de superfície criadas pelo preparo da ação de impacto direto das gotas da chuva, minimizando a dispersão das partículas de solo e, conseqüentemente, formação de selos e crostas, o que manteve melhor as capacidades de retenção e infiltração superficiais de água do solo. No tratamento sem mobilização de solo, por não terem sido criadas condições físicas de superfície favoráveis à retenção e à infiltração de água, a cobertura morta não teve efeito no retardamento da enxurrada.

\section{Perda de água da chuva na forma de enxurrada}

Os resultados desta variável estão apresentados na figura 2. Analisando os dados de perda de água em cada teste de chuva simulada, verifica-se que, independentemente do preparo e da cobertura, os 
Quadro 2. Tempo de início da enxurrada nos testes de chuva simulada realizados nos tratamentos estudados

\begin{tabular}{|c|c|c|c|c|c|c|c|}
\hline \multirow{2}{*}{ Preparo de solo } & \multicolumn{7}{|c|}{ Teste de chuva } \\
\hline & T1C1(1) & T1C2 ${ }^{(1)}$ & T1C3(1) & $\mathrm{T} 1 \mathrm{C} 4^{(1)}$ & $\mathbf{T} 2^{(1)}$ & T3(1) & $\mathbf{T} 4^{(1)}$ \\
\hline & \multicolumn{7}{|c|}{$-\min$} \\
\hline & \multicolumn{7}{|c|}{$\mathrm{Na}$ ausência de cobertura } \\
\hline Aração & $>20$ & $>20$ & 28 & 3 & 2 & 3 & 2 \\
\hline Aração e 2 gradagens & $>20$ & 18 & 3 & 1 & 1 & 2 & 2 \\
\hline \multirow[t]{2}{*}{ Sem preparo } & * & * & * & * & 2 & 2 & 2 \\
\hline & \multicolumn{7}{|c|}{$\mathrm{Na}$ presença de $60 \%$ de cobertura } \\
\hline Aração & $>20$ & $>20$ & $>30$ & 28 & 62 & 75 & 3 \\
\hline Aração e 2 gradagens & $>20$ & $>20$ & $>30$ & 25 & 12 & 28 & 5 \\
\hline Sem preparo & $*$ & * & $*$ & * & 2 & 1 & 1 \\
\hline
\end{tabular}

(1) T1, T2, T3 e T4 = testes de chuva 1, 2, 3 e 4, aplicados logo, 1, 20 e 35 dias após o preparo do solo, respectivamente; C1, C2, C3 e C4 = segmentos de chuva 1, 2, 3 e 4 de T1, com durações de 20, 20, 30 e 30 min, respectivamente; as chuvas de T2, T3 e T4 foram contínuas e tiveram 90 min de duração. * Não realizado o T1 neste tratamento.

maiores valores ocorreram nos testes de chuva contínua, de longa duração (T2, T3 e T4), graças à maior quantidade total de chuva aplicada nos mesmos. No entanto, a diferença na perda de água entre preparos, em cada teste de chuva, foi influenciada por ambas, a rugosidade superficial do solo e a cobertura por resíduo cultural. Assim, verifica-se que, na ausência de cobertura, a perda de água na aração e duas gradagens ocorreu a partir do terceiro segmento de chuva do primeiro teste (T1C3), porém baixa, enquanto, na aração, ela ocorreu somente a partir do quarto segmento (T1C4), mais baixa ainda, comparadas à perda de água dos testes subseqüentes. Isto deveu-se à elevada rugosidade superficial do solo e conseqüentemente à maior porosidade total da sua camada preparada, inicialmente presentes nestes tratamentos (Figura 1), o que proporcionou retardamento da enxurrada (Quadro 2) e aumento da retenção e da infiltração superficiais de água no solo. No entanto, essas condições físicas iniciais de superfície do solo, criadas pelo preparo, favoráveis à conservação da água, foram temporárias, tendo seus efeitos sido diminuídos no tempo, pela ação das chuvas aplicadas nos testes subseqüentes (T2, T3 e T4). Nestes testes, ainda na ausência de cobertura, as perdas de água foram altas, praticamente sem diferença entre os preparos, indicando que, na ausência de proteção da superfície do solo contra o impacto das gotas da chuva, a rugosidade superficial do solo induzida pelos preparos praticamente não teve efeito na retenção e na infiltração superficiais de água da chuva.

Analisando a perda de água na presença de $60 \%$ de cobertura do solo (Figura 2), verifica-se que por ela somente ocorreu a partir do segundo teste de chuva (T2), nos três preparos estudados, e em proporção substancialmente menor do que na

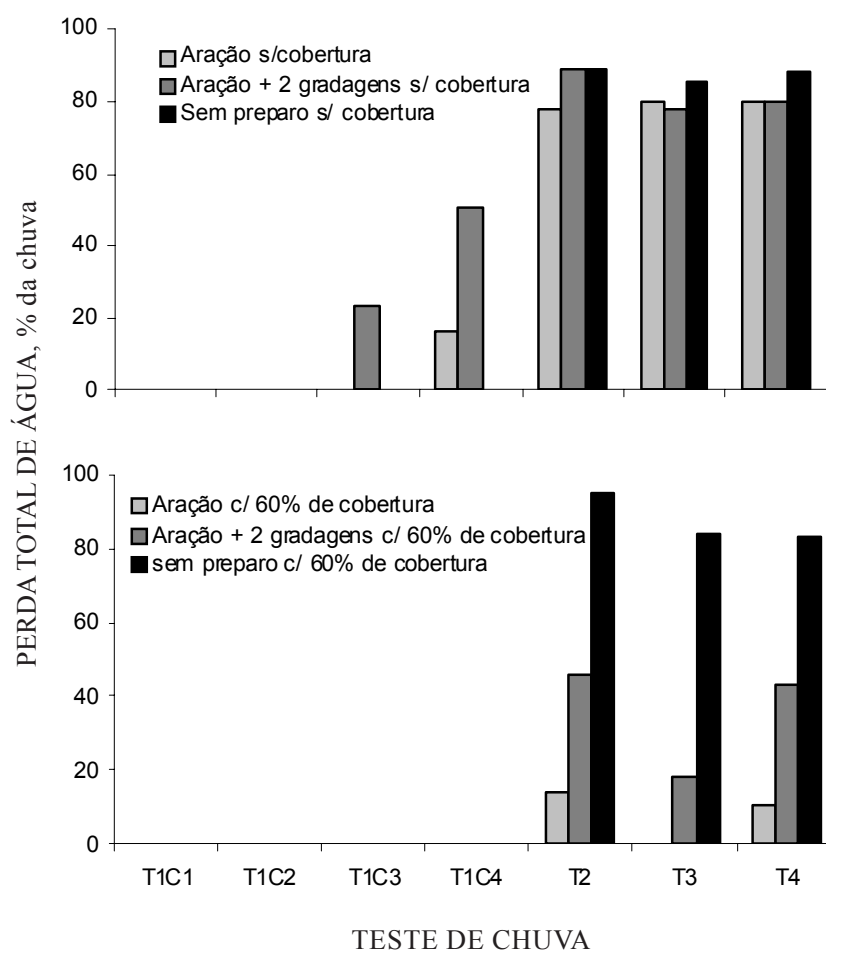

Figura 2. Perda total de água nos testes de chuva simulada realizados nos tratamentos estudados (T1, T2, T3 e T4 = testes de chuva 1, 2, 3 e 4, aplicados logo, 1, 20 e 35 dias após o preparo do solo, respectivamente; $\mathrm{C} 1, \mathrm{C} 2, \mathrm{C} 3$ e $\mathrm{C} 4=$ segmentos de chuva $1,2,3$ e 4 de $\mathrm{T} 1$, com durações de 20, 20, 30 e $30 \mathrm{~min}$, respectivamente; as chuvas dos Testes 2,3 e 4 foram contínuas e tiveram 90 min de duração. Obs: não foi realizado o Teste 1 no tratamento sem preparo do solo, tanto na ausência quanto na presença de cobertura). 
ausência de cobertura, exceto no tratamento sem preparo, que continuou com sua perda de água elevada, igualmente como na ausência de cobertura. A expressiva redução na perda de água por influência da cobertura morta nos tratamentos com solo mobilizado, embora com alguma diferença entre eles, comparada aos valores observados na ausência de cobertura, deveu-se à ação protetora da cobertura contra o selamento e o encrostamento, o que manteve melhor a infiltração da água da chuva no solo, em que pese ela não ter preservado os elevados valores de rugosidade superficial inicialmente criados pelo preparo, como já comentado. Por sua vez, a mais elevada perda de água na aração e duas gradagens, em relação à aração, deveu-se fundamentalmente à menor rugosidade superficial do solo (Figura 1). Já no tratamento sem preparo, a maior perda de água, comparada à dos solos mobilizados, foi devida à ação combinada de sua baixa rugosidade superficial (Figura 1) com o relativamente alto grau de consolidação de sua superfície, o que resultou em baixas retenção e infiltração superficiais de água da chuva, tendo grandemente facilitado o escoamento superficial. Deduz-se dos fatos apresentados a importância que a rugosidade superficial do solo tem na retenção e na infiltração de água da chuva na sua superfície, independentemente da cobertura do solo.

Quanto à perda total acumulada de água nos testes de chuva contínua, de longa duração (T2, T3 e T4), verifica-se, novamente, a importância que a cobertura do solo por resíduo cultural e a rugosidade superficial do solo induzida pelo seu preparo têm na conservação da água nas lavouras agrícolas (Figura 3). Na ausência de cobertura, a perda total acumulada de água foi alta nos três tratamentos de preparo (equivalente a $80 \%$ do volume total de chuva aplicado, na média dos mesmos), enquanto, na sua presença, ela foi reduzida nos dois tratamentos que sofreram mobilização de solo, porém mais na aração (equivalente a $8 \%$ do volume total de chuva aplicado) do que na aração e duas gradagens (equivalente a $38 \%$ do volume total de chuva aplicado), e continuou elevada no tratamento sem preparo (equivalente a $88 \%$ do volume total de chuva aplicado). Assim, na presença de cobertura, dos $288 \mathrm{~mm}$ de chuva aplicados nos três testes de chuva contínua, de longa duração (T2, T3 e T4), $92 \%$ infiltraram no solo na aração, 62 \% na aração e duas gradagens e 12 \% no sem preparo, percentuais que, respectivamente, equivalem a 265 e $179 \mathrm{~mm}$ de lâmina de água aproveitada nos tratamentos que sofreram mobilização de solo e apenas $35 \mathrm{~mm}$ no tratamento sem preparo. Estas diferenças, certamente, não podem ser ignoradas do ponto de vista de aplicação prática. A presença de cobertura por resíduo cultural, pois, é importante para a manutenção das condições físicas de superfície do solo criadas pelo preparo as quais são favoráveis à retenção e à infiltração de água, ao mesmo tempo que a presença de alguma rugosidade superficial no solo é importante nos solos ditos sem preparo ou não mobilizados, para o mesmo propósito.

$\mathrm{Na}$ tentativa de detectar tendência entre as variáveis envolvidas no assunto em pauta, na figura 4, é ilustrada a relação da perda de água da chuva na forma de enxurrada com a rugosidade superficial do solo induzida pelos métodos de preparo estudados. Considerando o baixo número de pontos na análise, verifica-se que na ausência de cobertura parece não ter havido relação entre perda de água e rugosidade superficial do solo induzida pelos métodos de preparo. No entanto, na presença de cobertura parece ter havido uma relação forte e decrescente, aparentemente linear, entre estas duas variáveis, com a perda de água diminuindo muito com o aumento da rugosidade superficial do solo. Certamente, esta relação deve ser mais bem

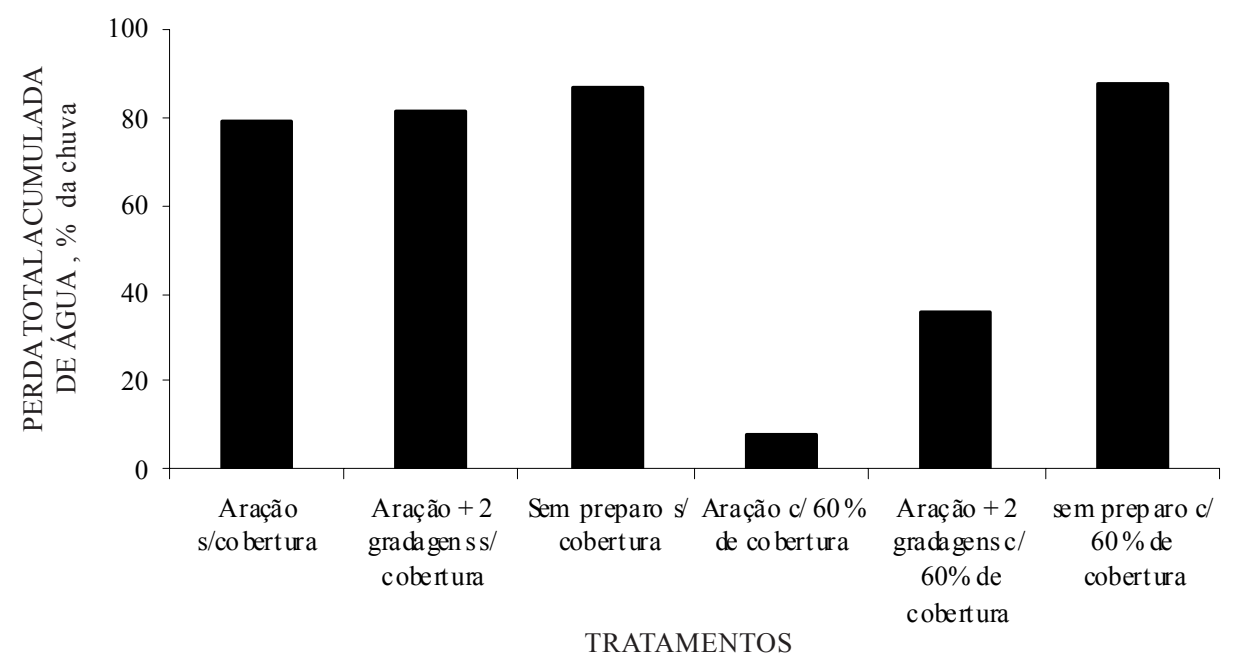

Figura 3. Perda total acumulada de água nos testes de chuva contínua (T2 + T3 + T4), de longa duração (90 $\mathrm{min})$, nos tratamentos estudados. 


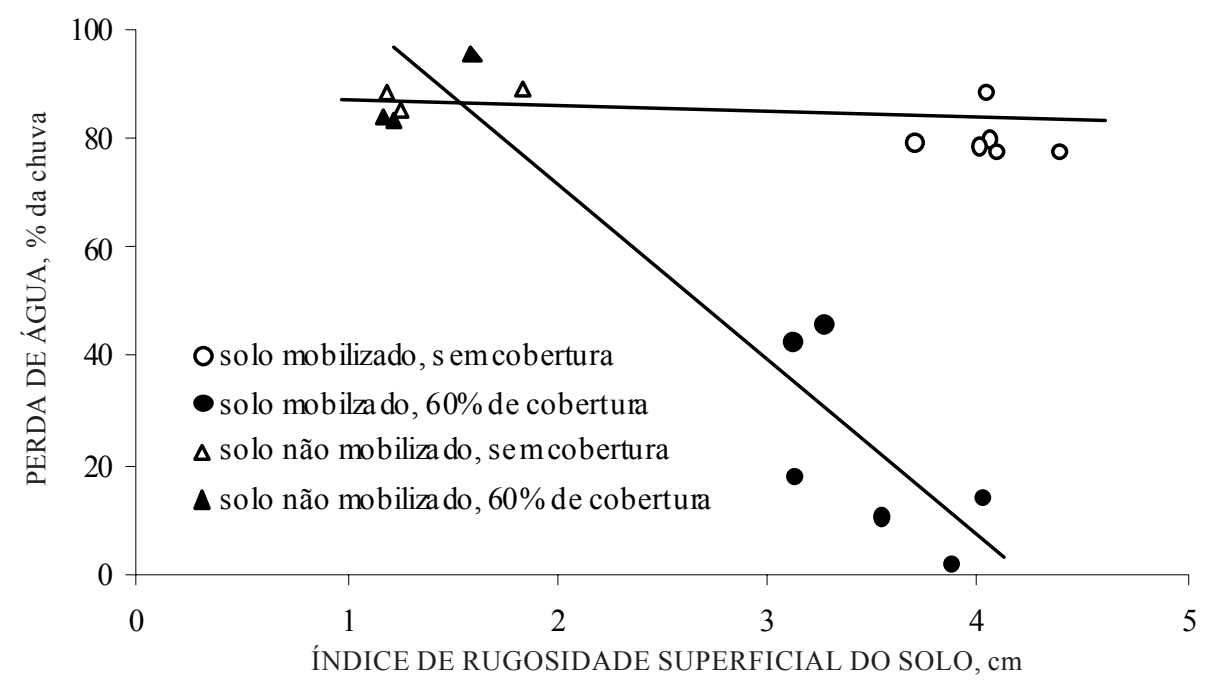

Figura 4. Relação da perda de água com o índice de rugosidade superficial do solo nos tratamentos estudados.

investigada, mas, desde já, observa-se a relação existente entre estas duas importantes variáveis de manejo sobre as terras de cultivo.

\section{Perda de solo por erosão hídrica}

Os valores desta variável estão apresentados nas figuras 5 e 6 , respectivamente, para cada teste de chuva simulada e para o somatório dos testes de chuva contínua, de longa duração. Verifica-se que tais perdas foram influenciadas pelos tratamentos estudados. Independentemente do preparo e da cobertura, os maiores valores de perda de solo ocorreram nos testes de chuva contínua, de longa duração (T2, T3 e T4 - Figura 5), em decorrência do maior tempo do processo erosivo nos solos. No entanto, as diferenças na perda de solo entre preparos, em cada teste de chuva simulada, foram influenciadas por ambas, a cobertura morta e a rugosidade superficial do solo, igualmente como aconteceu com a perda de água, porém de modo diferenciado.

$\mathrm{Na}$ ausência de cobertura (Figura 5), nos tratamentos que envolveram mobilização de solo (lembrando, o tratamento sem preparo não foi submetido à série de chuvas segmentadas), ocorreu perda de solo somente a partir do terceiro segmento de chuva do primeiro teste (T1C3) na aração e duas gradagens, porém baixa, e a partir do quarto segmento na aração (T1C4), também baixa, comparadas à perda de solo observada nos testes subseqüentes (T2, T3 e T4 - Figura 5). Isto é explicado pela elevada rugosidade superficial do solo inicialmente presente nestes tratamentos (Figura 1) e, conseqüentemente, pela maior porosidade total da sua camada preparada.

No entanto, igualmente como aconteceu com a perda de água, tais condições físicas iniciais de superfície do solo, criadas pelo preparo, favoráveis a sua conservação, foram temporárias, tendo seus efeitos sido diminuídos no tempo, pela ação das chuvas aplicadas nos testes subseqüentes (T2, T3 e T4). Nestes testes, na ausência de cobertura, as perdas de solo variaram tanto entre eles quanto entre os preparos, estes últimos especialmente no segundo teste (T2), contrariamente ao observado com a perda de água, a qual foi alta e similar em todos os preparos em tais testes (Figura 4). Estas diferenças na perda de solo entre preparos sob a ação de chuvas prolongadas indicam que, na ausência de proteção da superfície solo contra os agentes erosivos, a rugosidade superficial tem efeito importante na retenção dos sedimentos da erosão nas microdepressões formadas por ela, mais do que na retenção e na infiltração superficiais de água da chuva (Figuras 2 e 3). A menor perda de solo no tratamento sem preparo no segundo teste de chuva (T2), em relação à do tratamento aração e duas gradagens, bem como no terceiro e no quarto teste (T3 e T4), em relação aos dois tratamentos com mobilização de solo, ainda na ausência de cobertura, apesar do índice de rugosidade superficial ter sido o mais baixo entre os observados no estudo, é explicada pela consolidação do solo. Este fato deixou a superfície do solo em tal tratamento mais resistente à ação desagregadora da chuva e da enxurrada, comparada à superfície dos solos mobilizados, o que parcialmente compensou o efeito negativo da sua baixa rugosidade superficial em termos de capacidade de aprisionamento dos sedimentos da erosão.

Na presença de $60 \%$ de cobertura (Figura 5), a perda de solo foi drasticamente reduzida nos três preparos estudados, a ponto de ocorrer somente a partir do segundo teste de chuva (T2), na aração e duas gradagens, e no sem preparo e no último teste (T4), na aração. Estes resultados, mais uma vez, demonstram a importância que a cobertura do solo 


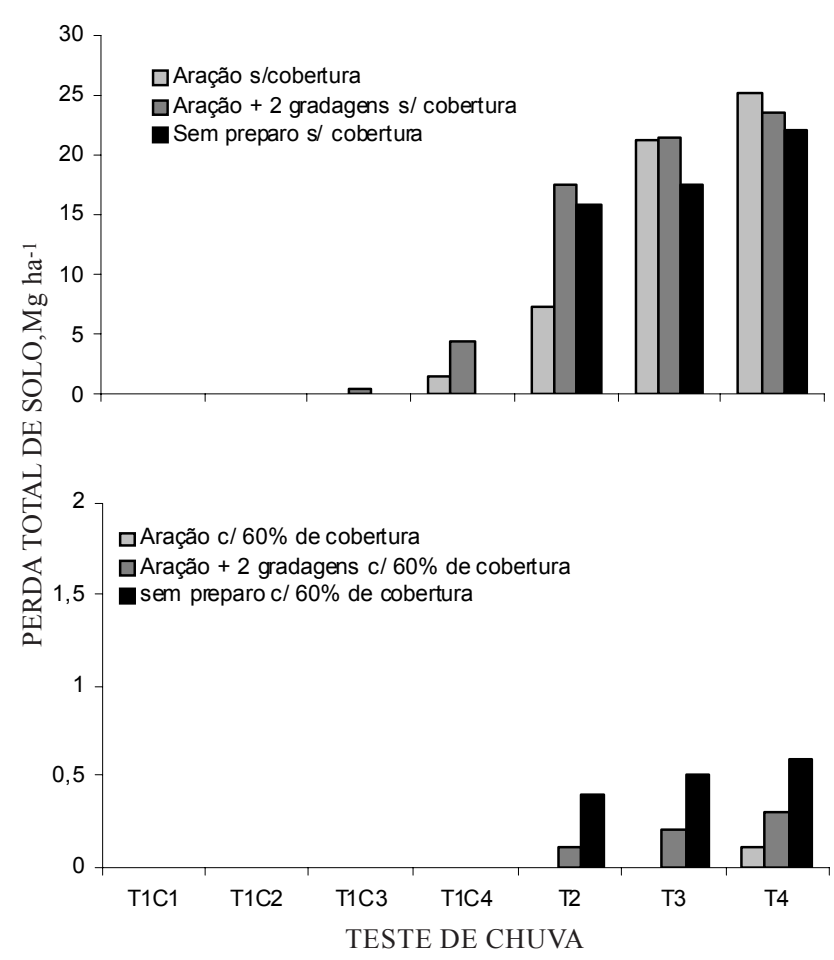

Figura 5. Perda total de solo nos testes de chuva simulada realizados nos tratamentos estudados (T1, T2, T3 e T4 = testes de chuva 1, 2, 3 e 4, aplicados logo, 1, 20 e 35 dias após o preparo do solo, respectivamente; $\mathrm{C} 1, \mathrm{C} 2, \mathrm{C} 3$ e $\mathrm{C} 4=$ segmentos de chuva $1,2,3$ e 4 de $T 1$, com durações de 20, 20, 30 e $30 \mathrm{~min}$, respectivamente; as chuvas dos Testes 2,3 e 4 foram contínuas e tiveram 90 min de duração. Obs: não foi realizado o Teste 1 no tratamento sem preparo do solo, tanto na ausência quanto na presença de cobertura).

por resíduos culturais tem no controle da erosão hídrica. De qualquer forma, em que pese o forte efeito da cobertura na redução da erosão (Figura 5), destaca-se a importância da rugosidade superficial como recurso adicional para se controlar, mais ainda, a perda de solo por tal fenômeno. Observa-se que, embora os muito baixos valores, a maior perda de solo sob cobertura ocorreu no tratamento sem preparo e a menor, na aração, ficando a aração e duas gradagens em posição intermediária, respectivamente, de acordo com sua baixa, alta e média rugosidade superficial e, conseqüentemente, com sua baixa, alta e média capacidade de reter os sedimentos da erosão. Estes fatos comprovam a importância da rugosidade superficial no controle da perda de solo por erosão hídrica, independentemente do nível e da presença de outras variáveis, o que já não acontece em relação ao controle da perda de água na forma de enxurrada (pelo menos em termos de magnitude do efeito). Para este último propósito, a rugosidade superficial do solo adquire importância maior quando, junto a ela, estiver associada boa cobertura por resíduo cultural (Figuras 2, 3 e 4), bem como ausência de selos e crostas nas suas microdepressões.

Os resultados de perda de solo (Figura 5) concordam com os do processo erosivo pela água da chuva. A presença de cobertura morta no solo protege sua superfície contra a ação de impacto direto das gotas da chuva, evitando ou diminuindo a desagregação inicial de suas partículas e, conseqüentemente seu transporte e a perda final de solo. Ainda, a cobertura morta serve como eficiente fonte de aprisionamento dos sedimentos da erosão e, ao mesmo tempo, eficiente obstáculo mecânico ao livre escoamento da enxurrada, o que reduz mais ainda a perda de solo, além do seu efeito positivo contra a formação de selos e crostas, o que irá auxiliar a infiltração de água no solo.

No entanto, se o selamento e, ou, encrostamento da superfície do solo já tiverem ocorrido, a cobertura morta pouco irá auxiliar a infiltração de água, especialmente nos solos não mobilizados, tendo em vista a baixa rugosidade superficial e a porosidade total da camada preparada. Por esta razão, apesar de efêmera, a presença de rugosidade superficial no solo deve ser sempre almejada nas terras de cultivo, tendo em vista que ela promove a retenção e a infiltração superficiais de água da chuva, reduz a velocidade e o volume do escoamento superficial e aprisiona os sedimentos da erosão. Com o passar do tempo, contudo, graças à ação das chuvas e das práticas culturais, a rugosidade superficial do solo é normalmente reduzida, diminuindo sua eficácia relativa de redução da erosão hídrica, tanto em termos de perda de solo, quanto de água. Estas considerações sobre cobertura morta e rugosidade superficial do solo explicam os resultados de perda de solo e de água obtidos no estudo.

Quanto à perda total acumulada de solo nos testes de chuva contínua, de longa duração (T2, T3 e T4), novamente verifica-se a importância que a cobertura do solo por resíduo cultural tem na conservação do solo nas lavouras agrícolas (Figura 6). Na ausência de cobertura, a perda total acumulada de solo foi alta nos três preparos estudados, denotando que a rugosidade superficial, por si só, não teve efeito na redução da perda de solo em tais chuvas. No entanto, na presença de cobertura, a perda total acumulada de solo foi drasticamente reduzida em todos os preparos. As razões para isto são as mesmas já arroladas, decorrentes da presença de cobertura morta no solo.

$\mathrm{Na}$ tentativa de detectar tendência entre as variáveis envolvidas no assunto em pauta, da mesma forma como foi feito para a perda de água, na figura 7, é ilustrada a relação da perda de solo com a rugosidade superficial induzida pelos métodos de preparo. Chama-se a atenção para o fato de que os pontos do tratamento sem preparo, apesar de constarem na figura 7 , não foram incluídos na 
análise, tendo em vista que, neste tratamento, esteve presente também o fator consolidação da superfície do solo, o qual, teórica e parcialmente, compensa o efeito negativo da baixa rugosidade superficial do solo na redução da perda de solo por erosão. Em que pese o relativamente baixo número de pontos na análise, igualmente como para a perda de água, verifica-se que, na presença de cobertura, parece não ter havido relação entre perda de solo e rugosidade superficial induzida pelos métodos de preparo, tendo em vista que o efeito de redução da primeira variável pela ação da segunda foi ocultado pela cobertura. No entanto, na ausência de cobertura, parece ter havido uma relação forte e decrescente, aparentemente linear, entre estas duas variáveis, com a perda de solo sendo grandemente reduzida com pequenos aumentos na rugosidade superficial do solo. Certamente, da mesma forma como foi comentado para a perda de água, esta relação deve ser mais bem investigada, mas, desde já, pode-se antever o tipo de relação existente entre estas duas importantes variáveis de manejo sobre as terras de cultivo.

\section{CONCLUSÕES}

1. A rugosidade superficial do solo induzida pelos métodos de preparo variou com o tipo de operação empregado, tendo sido alta, na aração, média, na aração e duas gradagens, e baixa, no sem preparo.

2. A alteração na rugosidade superficial do solo pela ação do preparo foi maior do que a pela ação da chuva.

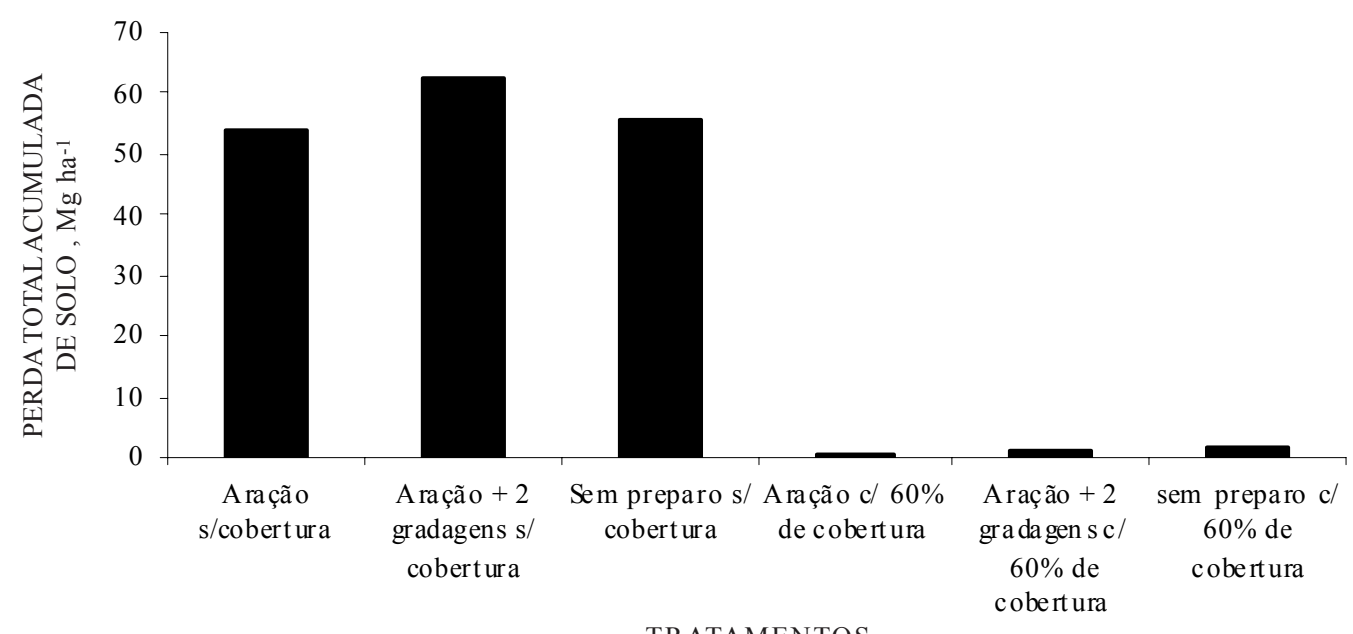

Figura 6. Perda total acumulada de solo nos testes de chuva contínua (T2 + T3 + T4), de longa duração (90 min), nos tratamentos estudados.

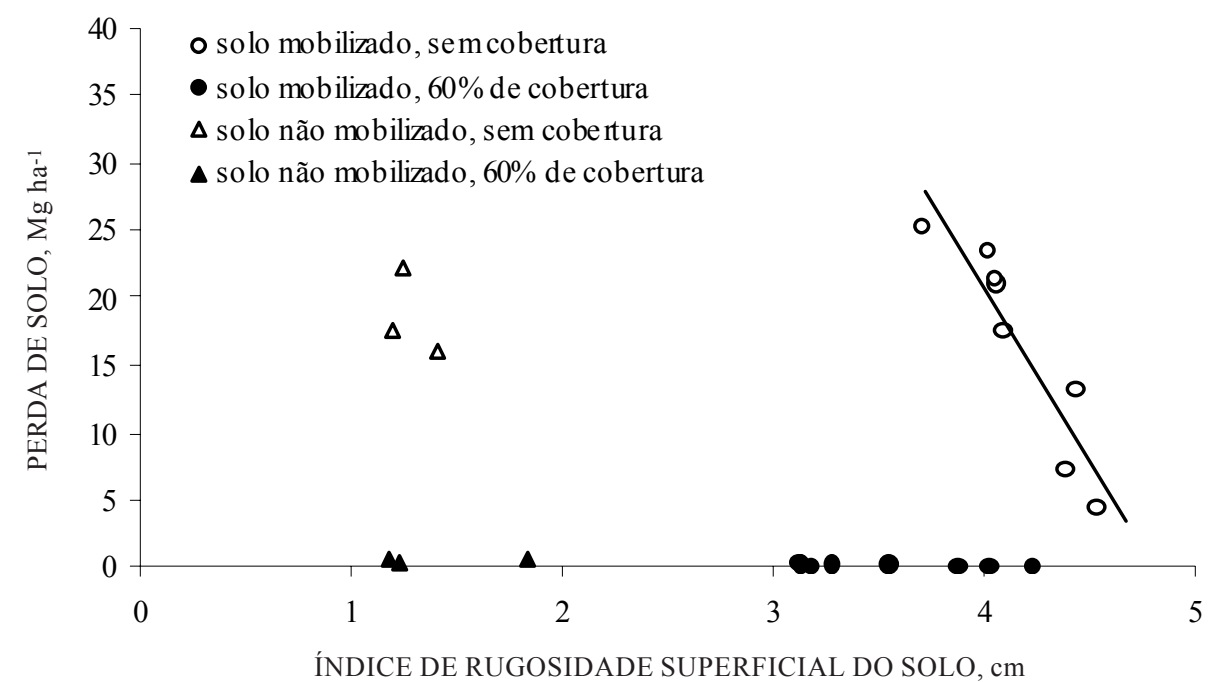

Figura 7. Relação da perda de solo com o índice de rugosidade superficial do solo nos tratamentos estudados. 
3. O maior decréscimo na rugosidade superficial do solo pela ação da chuva ocorreu já no primeiro evento, logo após o solo ter sido preparado, antes do início da enxurrada.

4. A rugosidade superficial do solo induzida pelos métodos de preparo impediu ou diminuiu as perdas de água e solo nos tratamentos com solo mobilizado nos segmentos de chuva de curta duração, aplicados logo após o preparo, independentemente da cobertura do solo, enquanto, nas chuvas contínuas subseqüentes, de longa duração, o efeito da rugosidade na redução da perda de água foi mais bem percebido na presença de cobertura (exceto o sem preparo, o qual permaneceu com a perda de água elevada sempre) e o de redução na de perda de solo na ausência de cobertura.

5. A cobertura morta adicionada ao solo não preservou a elevada rugosidade superficial inicialmente criada pelos preparos no solo degradado utilizado no estudo. Mesmo assim, ao final do experimento, ainda restava mais da metade da capacidade teórica inicial de retenção de água e de sedimento nas microdepressões formadas pela rugosidade.

\section{AGRADECIMENTOS}

Ao CNPq e à CAPES, pela concessão de bolsas de pós-graduação e de iniciação científica aos alunos envolvidos na pesquisa, aos colegas de Curso, em especial aos doutorandos Edemar Valdir Streck e Luiz Fernando Barros de Morais, e aos funcionários Ozébio e Paulo Lima, da EEA/UFRGS, pelo valioso auxílio na realização dos trabalhos de campo.

\section{LITERATURA CITADA}

ALLMARAS, R.R.; BURWELL, R.E. \& HOLT, R.F. Plow-layer porosity and surface roughness from tillage as affected by initial porosity and soil moisture at tillage time. Soil Sci. Soc. Am. Proc., 31:550-556, 1967.

BERTOL, I.; COGO, N.P. \& LEVIEN, R. Relações da erosão hídrica com métodos de preparo do solo na ausência e na presença de cobertura por resíduo cultural de trigo. R. Bras. Ci. Solo, 11:187-192, 1987.

BERTOL, I.; COGO, N.P. \& LEVIEN, R. Cobertura morta e métodos de preparo do solo na erosão hídrica em solos com crosta superficial. R. Bras. Ci. Solo, 13:373-379, 1989.

BERTOL, I.; COGO, N.P. \& MIQUELLUTI, D.J. Sedimentos transportados pela enxurrada relacionados à cobertura $\mathrm{e}$ rugosidade superficial do solo e taxa de descarga. Pesq. Agropec. Gaúcha, 3:199-206, 1997.

BURWELL, R.E.; ALLMARAS, R.R. \& AMEMIYA, M. A field measurement of total porosity and surface microrelief of soils. Soil Sci. Soc. Am. Proc., 27:697-700, 1963.
BURWELL, R.E.; ALLMARAS, R.R. \& SLONEKER, L.L. Structural alteration of soil surfaces by tillage and rainfall. J. Soil Water Conserv., 21:61-63, 1966.

BURWELL, R.E. \& LARSON, W.E. Infiltration as influenced by tillage-induced random roughness and pore space. Soil Sci. Soc. Am. Proc., 33:449-452, 1969.

CASTRO, L.G. Erosão hídrica relacionada à rugosidade superficial do solo na ausência e na presença de cobertura por resíduos culturais de aveia. Porto Alegre, Universidade Federal do Rio Grande do Sul, 1998. 120p. (Tese de Mestrado)

COGO, N.P. Effect of residue cover, tillage induce roughness, and slope lenght on erosion and related parameters. West Lafayette, Purdue University, 1981. 346p. (Tese de Mestrado)

COGO, N.P.; MOLDENHAUER, W.C. \& FOSTER, G.R. Effect of residue cover, tillage-induced roughness, and runoff velocity on size distribution of eroded soil aggregates. Soil Sci. Soc. Am. J., 47:1005-1008, 1983.

COGO, N.P.; MOLDENHAUER, W.C. \& FOSTER, G.R. Soil loss reductions from conservation tillage practices. Soil Sci. Soc. Am. Proc., 48:368-373, 1984.

COGO, N.P.; FOSTER, G.R. \& MOLDENHAUER, W.C. Flow rates-soil erosion relationships as affected by wheat residue cover: an attempt to define slope-length limits for conservation tillage. R. Bras. Ci. Solo, 20:465-483, 1996.

JOHNSON, C.B.; MANNERING, J.V. \& MOLDENHAUER, W.C. Influence of surface roughness and clod size and stability on soil and water losses. Soil Sci. Soc. Am. J., 43:772-777, 1979.

KUIPERS, H. A reliefmeter for soil cultivation studies. Neth. J. Agric. Sci., 255-262, 1957.

LARSON, W.E. Tillage requeriments for corn. J. Soil Water Conserv., 17:3-7, 1962.

LARSON, W.E. \& GILL, W.R. Soil physical parameters for designing new tillage systems. In: NATIONAL CONSERVATION TILLAGE, CONFERENCE. Ankeny, 1973. Proceedings. Ankeny, Soil Conservation Society of America, 1973.

LOPES, P.R.C.; COGO, N.P. \& CASSOL, E.A. Influência da cobertura vegetal morta na redução da velocidade da enxurrada e na distribuição de tamanho dos sedimentos transportados. R. Bras. Ci. Solo, 11:193-197, 1987a.

LOPES, P.R.C.; COGO, N.P. \& LEVIEN, R. Eficácia relativa de tipo e quantidade de resíduos culturais espalhados uniformemente sobre o solo na redução da erosão hídrica. R. Bras. Ci. Solo, 11:71-75, 1987b.

MORAIS, L.F. \& COGO, N.P. Comprimentos críticos de rampa para diferentes manejos de resíduos culturais em dois preparos conservacionistas de solo. R. Bras. Ci. Solo, 25:1041-1051, 2001.

NORTON, L.D.; COGO, N.P. \& MOLDENHAUER, W.C. Effectiveness of mulch in controlling soil erosion. In: EL SWAIFY, S.A.; MOLDENHAUER, W.C.\& LO, A., eds. Soil erosion and conservation. Ankeny, Soil Conservation Society of America, 1985. 80p. 
RENARD, K.G.; FOSTER, G.R.; WEESIES, G.A.; KOOL, D.K \& YODER, D.C. Predicting soil erosion by water: a guide to conservation planning with the revised universal soil loss equation (RUSLE). Washington, USDA, 1997. 384p. (Agr. Handbook, 703)

STRECK, E.V.; KAMPF, N.; DALMOLIN, R.S.D.; KLAMT, E.; NASCIMENTO, P.C. \& SCHNEIDER, P. Solos do Rio Grande do Sul. Porto Alegre, Universidade Federal do Rio Grande do Sul, 2002. 127p.
SWANSON, N.P. A rotating-boom rainfall simulator. Trans. Am. Soc. Agric. Eng., 8:71-72, 1965.

WISCHMEIER, W.H. Conservation tillage to control water erosion. In: NATIONAL CONSERVATION TILLAGE CONFERENCE, Ankeny, 1973. Proceedings. Ankeny, Soil Conservation Society of America, 1973. p.133-141.

WISCHMEIER, W.H. \& SMITH, D.D. Predicting rainfall erosion losses - a guide to conservation planning. Washington, USDA, 1978. 58p. (Agricultural Handbook, 537) 